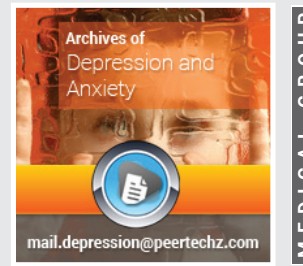

\section{A narrative review of major depressive disorder in children and adolescents}

\author{
Pratibha Gehlawat ${ }^{1}$ and Virender Kumar Gehlawat ${ }^{2}$ \\ ${ }^{1}$ Assistant Professor, Department of Psychiatry, All India Institute of Medical Sciences- Jodhpur, \\ Rajasthan, India \\ ${ }^{2}$ Associate Professor, Department of Paediatrics, Pt. B D Sharma, UHS, Rohtak, Haryana, India
}

Received: 07 March, 2020

Accepted: 05 May, 2020

Published: 06 May, 2020

*Corresponding author: Dr Pratibha Gehlawat, Assistant Professor, Department of Psychiatry, All India Institute of Medical Sciences, Jodhpur-342005 Rajasthan, India, Tel: +91 9671615649;

E-mail:drpratibhag2009@gmail.com

Keywords: Major depressive disorder; Children; Adolescents

https://www.peertechz.com

Check for updates

\begin{abstract}
Major depressive disorder is a substantial health problem that affects people of all ages. Researchers have estimated that 2-6\% of children and adolescents in the community suffer from depression. Major depressive disorder in children and adolescents is a chronic and relapsing condition, which does not remits spontaneously. A major proportion of depression in children and adolescents remains underdiagnosed and undertreated. Children with depression cannot just snap out of it on their own. If left untreated, depression in children and adolescents can lead to school failure, conduct disorder, anorexia and bulimia, school phobia, panic attacks, substance abuse, or even suicide. Depression in adolescents substantially heightens the risk of suicide. Hence, there is a need to identify and treat the same at the earliest to reduce its long-term negative consequences.
\end{abstract}

\section{Introduction}

Major depressive disorder is a common mental health problem in children and adolescents worldwide [1], but often unrecognised. The incidence and prevalence of depression in children and adolescents are on a rise over last few decades due to a competitive environment, burden of expectations of parents and teachers, peer pressure, etc. Major depressive disorder is a serious illness that can affect nearly every part of a young person's life and significantly impact his or her family. Depression is not always easy to be diagnosed in children. In children, symptoms of depression are often hidden by other behavioural and physical complaints. There may be comorbid psychiatric conditions associated which can further complicate diagnosis and management. Long-term negative consequences include poor academic performance, impaired social functioning, suicidal behaviour, homicidal ideation, and alcohol/substance abuse [2]. Therefore, early identification and management of depression among children are very important. With proper management, most children can get back on track with their lives. The goal of this review is to the understand the clinically relevant information about major depressive disorder in children and adolescents. The text will be divided into prevalence and risk factors, evaluation, early diagnosis and available treatment options. It is also mentioned that this is not a study involving clinical decision-making, but a collection of information about the importance of understanding major depressive disorder in children and adolescents.

\section{Prevalence and risk factors}

In terms of epidemiology, different studies which have evaluated the prevalence of depression in children and adolescents suggest that the prevalence varies according to the different age groups. Prevalence for infants vary from $0.5 \%$ to $3 \%$ in clinic setting, whereas in preschool children, the prevalence rate for major depression (1.4\%) [3]. Studies done in community settings suggest the prevalence of depression in children to ranges from $0.4 \%$ to $2.5 \%$ and among adolescents to be from $0.4 \%$ to $8.3 \%$ [4]. Lifetime prevalence through adolescence is reported as high as $20 \%$ [4]. Prior to puberty, depression is known to have equal gender representation; however, among adolescents, the male: female ratio is 1:2. Children who suffer from major depression are likely to have a family history of the disorder. Studies have shown that certain children have risk factors in their lives which could predispose them to depression or "trigger" depression. Some of the 
recognized risk factors are stress, cigarette smoking, loss of a parent or loved one, break-up of a romantic relationship, attention, conduct, or learning disorders, chronic illnesses, abuse or neglect and other trauma including natural disasters $[3,4]$.

\section{Evaluation and diagnosis}

According to Diagnostic and Statistical Manual, fifth revision (DSM-5) [5], depression is diagnosed in children and adolescents by using the same diagnostic criteria, as used for other age groups. The DSM- 5 suggests that the criteria of "presence of depressed mood" can be replaced by "irritable mood" in children and adolescents [5]. The diagnosis of persistent depressive disorder (equivalent of dysthymia) requires duration of 1 year in contrast to the 2-year duration required for adults [5]. However, it is considered that the criteria given in the DSM do not address the developmental variations in symptom manifestations, and hence it is required to modify the criteria to pick up depression in children. It usually takes more time to diagnose major depression in children than in adults. The diagnostic process includes interviews of parents and the child. Parents are more likely to report outward signs of depression, while the child may be more aware of inward signs. But children and adolescents with depression may have difficulty in properly identifying and describing their internal emotional or mood states. For example, instead of communicating how bad they feel, they may act out and be irritable toward others, which may be interpreted simply as misbehaviour or disobedience. Research has also found that parents are even less likely to identify major depression in their adolescents than are the adolescents themselves. Sometimes a parent's report is skewed by the parent's own agenda, hence, school and other outside reports are useful.

Characteristics of depression, according to present nosological system, that usually occur in children, adolescents, and adults include $[6,7]$ :

- Persistent sad and irritable mood

- Loss of interest or pleasure in activities once enjoyed

- Significant change in appetite and body weight

- Difficulty sleeping or oversleeping

- Physical signs of agitation or excessive lethargy and loss of energy

- Feelings of worthlessness or inappropriate guilt

- Difficulty concentrating

- Recurrent thoughts of death or suicide

Characteristics of childhood depression [6,7]: The way symptoms are expressed varies with the developmental level of the youngster.

Symptoms associated with depression more commonly in children and adolescents than in adults include:
- Frequent vague, nonspecific physical complaints (headaches, stomach aches)

- Frequent absences from school or unusually poor school performance, School refusal or excessive separation anxiety

- Outbursts of shouting, complaining, unexplained irritability, or crying

- Chronic boredom or apathy

- Lack of interest in playing with friends

- Alcohol or drug abuse

- Withdrawal, social isolation, and poor communication

- Excessive fear of or preoccupation with death

- Extreme sensitivity to rejection or failure

- Unusual temper tantrums, defiance, or oppositional behavior

- Reckless behaviour

- Difficulty maintaining relationships

- Regression (acting babyish, resumption of wetting or soiling after toilet training)

\section{- Increased risk-taking behavior}

If several of the above characteristics are present, it is a cause for concern and may suggest the need for professional evaluation for depressive episode in children.

\section{Assessment of comorbidities}

It is well known that comorbidity is a rule rather than the exception in children and adolescents with depression. The common psychiatric comorbid conditions include anxiety disorders, substance use disorder, personality disorder, conduct disorder, oppositional defiant disorder, AttentionDeficit Hyperkinetic Disorder (ADHD), and dissociative/ conversion disorder. Hence, a detailed evaluation of children and adolescents with depression should be done for comorbid psychiatric conditions [8]. Depression may be attributed to various physical illnesses, therefore, a through physical examination must be carried out in all children and adolescents presenting with depressive features. In case any physical illness is suspected, help of pediatrician and other specialist can be taken.

Children and adolescents with depression are at significantly increased suicidal risk [9]. Therefore, assessment of children and adolescents with depression include the assessment of suicidal risk. The risk of suicidal behaviour should not be underestimated. Children must be asked about the presence of suicidal ideation, specific plans for self-injury, and any history of actual self-harm or overt threats or gestures [9]. 
Hence, a comprehensive assessment of children and adolescents presenting with depressive symptoms should be done including the psychosocial evaluation of family discord and family psychopathology for the proper management.

\section{Treatment}

A large number of strategies have been developed for the treatment of depression. Many of these approaches can be implemented individually, in groups, or family therapy environment. Treatment options for the management of depression in children and adolescents include psychotherapies, antidepressants, Electroconvulsive Therapy (ECT), and other somatic treatments such as repetitive transcranial magnetic stimulation (rTMS) [10]. The management should be multimodal. Patients as well as parents must be informed about the nature, course, and treatment of this disease. There is considerable evidence to suggest that interventions which emphasize treatment of the family, and not just the "identified patient," are critical to positive treatment outcomes. Peer group approaches have been found to be effective for children. Play therapy has been found appropriate with younger children $[10,11]$.

Different treatment methods that are used for depression are as follows:

1. Cognitive-Cognitive approaches utilize specific strategies designed to alter negatively-based cognitions. Depressed patients are trained to recognize the connections between their thoughts, feelings, and behavior; to monitor their negative thoughts; to challenge their negative thoughts with evidence; to substitute more reality-based interpretations for their usual interpretations; and to focus on new behaviors outside treatment [12].

2. Behavioral - Behavioral approaches designed to increase pleasant activities include several components such as self-monitoring of activities and mood; identifying positively reinforcing activities that are associated with positive feelings; increasing positive activities; and decreasing negative activities [11].

3. Social Skills - Social skills training consists of teaching children how to engage in several concrete behaviors with others. Initiating conversations, responding to others, refusing requests, making requests, etc. Children are provided with instructions, modeling by an individual or peer group, opportunities for role playing, and feedback. The object of this approach is to provide children with an ability to obtain reinforcement from others.

4. Self-Control - Self-control approaches are designed to provide the self-control strategies including selfmonitoring, self-evaluation, and self-reinforcement. Depressive symptoms are considered to be the result of deficits from one or more areas and are reflected in attending to negative events, setting unreasonable self- evaluation criteria for performance, setting unrealistic expectations, providing insufficient reinforcement, and excessive self-punishment.

5. Interpersonal - Interpersonal approaches focus on relationships, social adjustment, and mastery of social roles. Treatment usually includes non-judgmental exploration of feelings, elicitation and active questioning on the part of the therapist, reflective listening, development of insight, exploration and discussion of emotionally laden issues, and direct advice.

6. Medications - Efficacy of many antidepressants has been evaluated in randomized controlled trials (RCTs) in children and adolescents. Antidepressants which have been evaluated in children and adolescents include imipramine, des-imipramine, clomipramine, nortriptyline, amitriptyline, fluoxetine, paroxetine, escitalopram, sertraline, duloxetine, venlafaxine, nefazodone, and mirtazapine [13,14]. The studies concluded that only fluoxetine was significantly better than placebo $[15,16]$. The multicentric National Institute of Mental Health-funded study, i.e., Treating Adolescent Depression Study (TADS) [17], which compared the use of fluoxetine alone, CBT alone, or combination of both, concluded that combination of CBT and fluoxetine offered the highest treatment response rates followed by response rate to fluoxetine alone. It is also documented that use of antidepressants is associated with an increased risk of suicidal behavior, compared to placebo [18].

Among the various antidepressants, the Food and Drug Administration (FDA) of United States has approved the use of fluoxetine in children aged 8 years or above [15] and use of escitalopram in children aged 12 years or above $[19,20]$. One of the major controversies with respect to the use of antidepressants among children and adolescents is the risk of suicidal behavior. Therefore, the FDA has issued a black box warning against the use of antidepressants among children and adolescents. Accordingly, cautious approach need to be considered while using antidepressants among children and adolescents, and they must be closely monitored for any treatment-emergent suicidal behavior.

Another important risk while using antidepressants among children and adolescents is medication-induced behavioral activation. It is characterized by the symptoms of irritability, agitated and aggressive behavior, anxiety symptoms, restlessness, hostility, akathisia, hypomania/mania, and emergence of psychotic symptoms. There antidepressantassociated behavioral activation has been found to be associated with the use of higher doses of medications [17]. Hence, the children and adolescents receiving antidepressants must be closely monitored while starting antidepressant medication and during the period of change of doses of antidepressant medications.

Medication should be considered as first-line of management for children and adolescents with severe symptoms that 
would prevent effective psychotherapy, those who are unable to undergo psychotherapy, those with psychosis, and those with chronic or recurrent episodes. Following remission of symptoms, continuation treatment with medication and/or psychotherapy for at least six to nine months is recommended, given the high risk of relapse and recurrence of depression. Discontinuation of medications, as appropriate, should be done gradually over a period of 6 weeks or longer $[21,22]$.

\section{Conclusion}

It is concluded that children and adolescents should be screened for major depressive disorder if pervasive behavioural changes are observed by the family, friends and teachers. When a youngster screens positive, a comprehensive diagnostic evaluation by a mental health professional is warranted. The misconception regarding children that they can just get over depression should not be there. Also, one should keep in mind that children have to deal with peer acceptance, school life, and any pressures or expectations that their parents have. Therefore, children are more prone to suffer from depression. Therefore, early diagnosis and proper treatment of children with depression should be done incorporating family, friends and teachers to improve self-image and a fully functional happy life.

\section{Author contribution}

The manuscript has been read and approved by all the authors, that the requirements for authorship have been met, and each author believes that the manuscript represents honest work.

\section{References}

1. Lopez A, Mathers C, Ezzati M, Jamison D, Murray CJL (2006) Global burden of disease and risk factors. Washington: Oxford University Press and the World Bank. Link: https://bit.ly/2Wx2Vn5

2. Birmaher B, Ryan ND, Williamson DE, Brent DA, Kaufman J, et al. (1996) Childhood and adolescent depression: A review of the past 10 years Part II. J Am Acad Child Adolesc Psychiatry 35: 1575-1583. Link: https://bit.ly/2YENDiM

3. Fleming JE, Offord DR (1990) Epidemiology of childhood depressive disorders: A critical review. J Am Acad Child Adolesc Psychiatry 29: 571-580. Link: https://bit.ly/2zdjPPO

4. Seeley J, Rohde P, Lewinsohn P, Clarke G (2002) Depression in youth: Epidemiology, identification, and intervention. In M. Shinn, H. Walker, \&. G. Stoner (Eds.), Interventions for academic and behavior problems II: Preventive and remedial approaches 885-912.

5. Diagnostic and Statistical Manual of Mental Disorders (2013) Diagnostic and Statistical Manual of Mental Disorders, Fifth Edition. Arlington, VA: American Psychiatric Association.

6. Luby JL, Heffelfinger AK, Mrakotsky C, Brown KM, Hessler MJ, et al. (2003) The clinical picture of depression in preschool children. J Am Acad Child Adolesc Psychiatry 42: 340-348. Link: https://bit.ly/3drwA8h

7. Collishaw S (2009) Trends in adolescent depression: a review of the evidence.
In: Yule W, editor. Depression in childhood and adolescence: the way forward. London: Association of Child and Adolescent Mental Health 7-18. Link: https://bit.ly/2xDIJaR

8. Angold A, Costello EJ (1993) Depressive comorbidity in children and adolescents: empirical, theoretical, and methodological issues. Am J Psychiatry 150: 1779-1791. Link: https://bit.ly/2W4XsVw

9. Borowsky IW, Ireland M, Resnick MD (2001) Adolescent suicide attempts: risks and protectors. Pediatrics 107: 485-493. Link: https://bit.ly/2SF6y9]

10. Weersing VR, Jeffreys M, Do MT, Schwartz KT, Bolano C (2017) Evidence base update of psychosocial treatments for child and adolescent depression. J Clin Child Adolesc Psychol 46: 11-43. Link: https://bit.ly/2YCvZfz

11. Cox GR, Callahan P, Churchill R, Hunot V, Merry SN, et al. (2014) Psychological therapies versus antidepressant medication, alone and in combination for depression in children and adolescents. Cochrane Database Syst Rev CD008324. Link: https://bit.ly/2LOByfY

12. Reinecke MA, Ryan NE, DuBois DL (1998) Cognitive-behavioral therapy of depression and depressive symptoms during adolescence: A review and meta-analysis. J Am Acad Child Adolesc Psychiatry 37: 26-34. Link: https://bit.ly/2xHUfSC

13. Garland EJ (2004) Facing the evidence: antidepressant treatment in children and adolescents. CMAJ 170: 489-491. Link: https://bit.ly/2zisLTK

14. Hetrick SE, Merry SN, McKenzie J, Sindahl P, Proctor M (2009) Selective serotonin reuptake inhibitors (SSRIs) for depressive disorders in children and adolescents (Review). Cochrane Database Syst Rev 1.

15. Emslie GJ, Rush AJ, Weinberg WA, Kowatch RA, Hughes CW, et al. (1997) A double-blind, randomized, placebo-controlled trial of fluoxetine in children and adolescents with depression. Arch Gen Psychiatry 54: 1031-1037. Link: https://bit.ly/2YDmXiA

16. Emslie GJ, Heiligenstein JH, Wagner KD, Hoog SL, Ernest DE, et al. (2002) Fluoxetine for acute treatment of depression in children and adolescents: a placebo controlled, randomized clinical trial. J Am Acad Child Adolesc Psychiatry 41: 1205-1215. Link: https://bit.ly/3fpbMQn

17. March JS, Vitiello B (2009) Clinical messages from the Treatment fo Adolescents With Depression Study (TADS). Am J Psychiatry 166: 1118-1123. Link: https://bit.ly/2YFfy2m

18. Curry J, Rohde P, Simons A, Silva S, Vitiello B, et al. (2006) Predictors and moderators of acute outcome in the treatment for adolescents with depression study (TADS). J Am Acad Child Adolesc Psychiatry 45: 1427-1439. Link: https://bit.ly/3bbiNRs

19. Emslie GJ, Ventura D, Korotzer A, Tourkodimitris S (2009) Escitalopram in the treatment of adolescent depression: A randomized placebo-controlled multisite trial. J Am Acad Child Adolesc Psychiatry 48: 721-729. Link: https://bit.ly/2L6DQd

20. Findling RL, Robb A, Bose A (2013) Escitalopram in the treatment of adolescent depression: A randomized, double-blind, placebo-controlled extension trial. J Child Adolesc Psychopharmacol 23: 468-480. Link: https://bit.ly/3c70Jt2

21. Hughes CW, Emslie GJ, Crismon ML, Posner K, Birmaher B, et al. (2007) Texas children's medication algorithm project: Update from Texas Consensus Conference Panel on medication treatment of childhood majo depressive disorder. J Am Acad Child Adolesc Psychiatry 46: 667-686. Link: https://bit.ly/3fqDQ64

22. Grover S, Avasthi A (2019) Clinical practice guidelines for the management of depression in children and adolescents. Indian J Psychiatry 61: 226-240. Link: https://bit.ly/2A1kdRH

Copyright: @ 2020 Gehlawat P, et al. This is an open-access article distributed under the terms of the Creative Commons Attribution License, which permits unrestricted use, distribution, and reproduction in any medium, provided the original author and source are credited.

Citation: Gehlawat P, Gehlawat VK (2020) A narrative review of major depressive disorder in children and adolescents. Arch Depress Anxiety 6(1): 019-022. DOI: https://dx.doi.org/10.17352/2455-5460.000046 